Jana Ndiaye Berankova*

\title{
The Immanence of Truths and the Absolutely Infinite in Spinoza, Cantor, and Badiou
}

The relationship between mathematics and ontology and the slogan "mathematics is ontology" has been a constant topic of investigation among thinkers who follow Alain Badiou's philosophical project. In 2018, at the conference Thinking the Infinite at the National Gallery in Prague, Badiou was supposed to give a talk proving the logical necessity of mathematical ontology. However, instead of providing the final proof that some members of the public were asking for, he delivered a different talk reworked at the last minute. He elicited great perplexity in the room by retracting the slogan "mathematics is ontology" for being nothing but an advertising simplification of a necessarily complex problem. ${ }^{1}$ He observed that this clear and easily memorable slogan falls into the sphere of the doxa and cannot exhaust the nuanced relationship between the two fields. My intention in the present article will be to provide an interpretation of these puzzling remarks along with an exegesis of the mathematical concepts that appear in the recently published third volume of Being and Event: The Immanence of Truths. In this third volume, Badiou relies on the mathematical theory of large cardinals, which addresses sets and classes so large that they can almost approximate the entire universe of numericity. He proposes a renewed theory of the absolute "substance" and of the attributes of the absolute. As abstract and complex as such thinking might seem, it builds upon problems which appeared - although in their naïve and schematic form - already in the mathematico-philosophical considerations of Georg Cantor. By reading Badiou's and Cantor's texts closely together, we might be able to comprehend the articulation of philosophy and mathematics and the role played by philosophical choices.

Alain Badiou, “Ontologie et mathématiques : Théorie des Ensembles, théorie des Catégories, et théorie des Infinis, dans L'Être et l'événement, Logiques des mondes et L'immanence des vérités". 


\section{Mathematical ontology and its consequences}

Did Badiou truly disavow the relationship between ontology and mathematics, or more broadly, between philosophy and mathematics? My conviction is that the response to this question might not be scandalous at all: "the discourse of Prague" constitutes nothing but a clarification of the hierarchy between these two fields. Badiou posits that "the thinking of being is a thinking on different forms of the multiple." ${ }^{2}$ He departs from the philosophical statement "being is the multiplicity-without-the-one." ${ }^{3}$ This starting point is not a mathematical statement. It would thus be misleading to say that "ontology is mathematics" for the latter expression would imply that we can derive knowledge of being directly from mathematics without passing through philosophical decisions and that mathematical inventions must have a direct and immediate effect on our understanding of Being. "Being is the multiplicity-without-the-one" is nothing but an initial philosophical decision; it is the philosopher's choice: the philosopher chooses this position over another one by comparing their possible consequences. In other words, the decision situated at the beginning of any philosophical system is an initial "wager", a "working hypothesis", perhaps something like a philosophical "axiom". Such an "axiom" can be legitimated only by the richness of its consequences. The dialogue between mathematics and philosophy can be portrayed as follows: "a philosopher outlines a certain idea, and then uses mathematics, wherein this idea can be verified, and in the end returns to philosophy." It is the "very construction of the [philosophical] system [that] proves the statement. This means that this initial statement is $a$ posteriori proven and vindicated thanks to the scope of its consequences. But we never have demonstrative certainty which would resemble mathematical formalism."' In the present volume, Badiou states similarly that "the alliance organized between mathematics and philosophy becomes strong only when we observe its consequences." In other words, mathematics is but philosophy's methodological tool for verifying its initial philosophical hypotheses. The phi-

\footnotetext{
2 Interview with Alain Badiou on The Immanence of Truths, Paris, 13 February 2018.

3 See p. 22 in the present volume.

4 See p. 30 in the present volume.

5 Jana Beránková, “Communism is a New Idea, Interview with Alain Badiou by Jana Beránková”, Contradictions 2 (2/2018), p. 118.

6 Ibid., 118.

7 See p. 22 in the present volume.
} 
losopher needs mathematics in order to build a method, and it is in this sense that a great part of ontology remains "mathematical", and yet we cannot affirm that philosophical statements are deduced directly from mathematics. To the philosopher, mathematics is but a modality to develop his or her thought; the origin and the finality of thinking remains philosophical. In fact, ontology is grounded in philosophy, not in science. In Prague, Badiou merely clarified the hierarchy between these two fields by alluding to the ineluctable arbitrariness of philosophical decisions; in no manner did he reject the relationship between ontology and mathematics. Instead of "mathematics is ontology," it might be more exact to say that "ontology uses mathematics as a methodological instrument for creating a possibility of our understanding of being." Mathematics is a mere condition of philosophy along with politics, art, and love. The relationship between philosophy and mathematics is not that of "suture": philosophy is not sutured to anything; it highlights the existence of truth procedures in its conditions (science qua mathematics being one of them).

Note that in the above cited passages, the relationship between mathematics and philosophy is portrayed on the basis of inductive, not deductive, reasoning. Here, the induction generates the possibility of building up a philosophical system from mathematical grounds. As long as mathematics assists philosophers by successfully elucidating otherwise unsolvable problems, its use in ontology is legitimate. Such reasoning sounds surprisingly Gödelian, for it can call to mind the concluding paragraph of Kurt Gödel's 1947 article "What is Cantor's Continuum Problem?": “There might exist axioms so abundant in their verifiable consequences, shedding so much light upon a whole field, and yielding such powerful methods for solving problems (and even solving them constructively, as far as that is possible) that, no matter whether or not they are intrinsically necessary, they would have to be accepted at least in the same sense as any well-established physical theory." Badiou - who valued Gödel's article for the emphasis it placed on the role that mathematical intuition and axiomatic decisions play in solving mathematical problems ${ }^{9}-$ remarked that "Every thought - and therefore, mathematics - sets off decisions (intuitions)

8 Kurt Gödel, “What is Cantor’s Continuum Problem?”, in Collected Works, Vol. II, Publications 1938-1974, Oxford University Press, Oxford 1990, p. 261.

9 See Badiou's comments on Gödel's article in Briefings on Existence: A Short Treatise on Transitory Ontology, State University of New York Press, Albany 2006, p. 92. 
from the standpoint of the undecidable (of nondeductible inference)." ${ }^{\prime 10}$ Ontology's use of mathematics is nothing but an initial decision that can be justified $a$ posteriori by the solutions it provides to otherwise unsolvable problems.

Critics of Badiou's mathematical ontology (some of whom are included in this volume) tend to see as deduction what in reality is inductive reasoning. The criticism usually follows this trajectory: If set theory is ontology (i.e. a rational discourse on being qua being defined as an inconsistent multiplicity without the one), could some other mathematical theory (e.g. category theory, mereology $)^{11}$ be ontology too? Why should we privilege set theory, an obscure field of knowledge that seems to be but a burden to many working mathematicians? These questions are legitimate but also tautological. For had we departed from a different philosophical axiom, e.g. that "being is a pure multiplicity without the one," a different mathematical or scientific theory might be much more suitable to our thinking. It is very likely possible to build ontology on a different basis than a set-theoretical basis. Any true criticism cannot dispense with the long and laborious task of system building. The usefulness of a given mathematical theory for philosophical thought can only be seen after we have sketched and exhausted its consequences in the domain of philosophy. Thinking moves from ontology to mathematics and not vice versa. A correct reasoning cannot be "there is theory y in mathematics, therefore being must be $\mathrm{x}$," but rather: "being is $\mathrm{x}$, therefore we should use mathematical theory y to develop our reflection." And even this second reasoning can be vindicated only a posteriori depending on the fruitfulness of its consequences. Philosophy cannot have the certitude of a mathematical formalism; it is consistent but necessarily incomplete. It begins with an axiom and not with a totalising origin that would close its field of the possible. Philosophical axioms, the statements in which the long trajectory of thought originates, can be verified only a posteriori, after accomplishing a certain philosophical journey. Only by elaborating a different and similarly complex philosophical system grounded in a competing statement that "ontology is $y$ " will it be possible to measure the richness of its consequences with those of Badiou's set-theoretical ontology. Philosophical "working hypotheses” do not

10 Alain Badiou, Briefings on Existence: A Short Treatise on Transitory Ontology, State University of New York Press, Albany 2006, p. 95.

${ }^{11}$ See Roland Bolz's article in the present volume, "Mathematics is Ontology? A Critique of Badiou's Ontological Framing of Set Theory". 
act immediately but with delay. Thus, the question "Why is ontology not y?" constitutes a philosophical suspicion, not a true criticism. It can become a seriously voiced criticism only when - accompanied by the effect of time - it has gone through a patient and laborious procedure of system-building.

Badiou's portrayal of the relationship between philosophy and mathematics reminds us of Georg Cantor's affirmation of the freedom of mathematics in the 1883 Foundations of a General Theory of Manifolds, a text that was reprinted in 1969, in the $10^{\text {th }}$ and last issue of Cahiers pour l'Analyse on "La Formalisation", which was coedited by Badiou. ${ }^{12}$ According to Cantor, in the introduction of new numbers the mathematician is "only obliged to give definitions of them which will bestow such a determinacy and, in certain circumstances, such a relation to the older numbers that they can in any given instance be precisely distinguished. As soon as a number satisfies all these conditions, it can and must be regarded in mathematics as existent and real." ${ }_{13}$ According to Cantor, mathematical concepts appear as causa sui; they contain in themselves an almost functionalist corrective according to which if a concept "is fruitless or unsuited to its purpose, then that appears very soon through its uselessness, and it will be abandoned for its lack of success." ${ }_{14}$ Like the above-mentioned philosophical decisions, mathematical concepts are legitimated by their consequences, by inductive reasoning or by reductio ad absurdum. However, it would be absurd to pretend that philosophy can "accumulate" knowledge in the same way as mathematics does and that philosophical statements do not contradict the work of their predecessors. Philosophers' desire for scientificity makes them confront new conjectures with the work of previous masters (in Badiou's case, such confrontation appears namely in his seminars examining the work of thinkers such as Plato, Leibniz, Spinoza, and Kant). And yet, a rigour equivalent to mathematical formalism can be never attained by philosophy.

12 See Georg Cantor, “Fondements d'une théorie générale des ensembles”, Cahiers pour l'Analyse (10/1969), pp. 35-52.

13 Georg Cantor, "Foundations of a General Theory of Manifolds: A Mathematico-Philosophical Investigation into the Theory of the Infinite”, in From Kant to Hilbert: A Sourcebook in the Foundations of Mathematics, Vol. II, ed. William Ewald, Clarendon Press, Oxford 2005, p. 896.

$14 \quad$ Ibid., 896. 


\section{Infinitum Absolutum: the actual or potential infinite?}

Much of the confusion about the relationship between mathematics and philosophy might have been spurred by the fact that Badiou began his trajectory referring to problems proper to the philosophy of mathematics without practicing a "philosophy of mathematics". Such a detour through this field and mathematics' own "crisis of foundations" had the function of creating space for a new realist orientation of thought and of "break[ing] with the linguistic turn that has seized philosophy." ${ }^{15}$ Badiou rejected the Aristotelian and Leibnizian algorithmic and constructive vision of mathematics and inscribed his own philosophical project into the genealogy of Plato and Spinoza. In some cases, he had to redefine terms commonly used in the philosophy of mathematics. For instance, he proposed that instead of the definition of mathematical Platonism put forward by Benaceraff and Putnam, i.e. the belief that "mathematical objects are independent of our minds and, unlike physical objects, do not interact with our bodies to cause alterations in our brains that lead ultimately to knowledge of them," ${ }^{\prime 6}$ Platonism should be understood as "the recognition of mathematics as a thought that is intransitive to sensible and linguistic experience, and dependent on a decision that makes space for the undecidable, while assuming that everything consistent exists. ${ }^{{ }_{17}}$ Badiou also frequently referred to the crisis of the foundations in mathematics as a moment in which mathematics was "compelled to think its thought as the immanent multiplicity of its own unity." ${ }^{{ }_{18}}$ However, he rejected all three major issues of this crisis formulated in the first half of the $20^{\text {th }}$ century (i.e. Frege's and Russell's logicism, Hilbert's approach to conceiving of mathematics as a complete and consistent formal system, and Brouwer's intuitionism recognising only the existence of denumerable sets). He renounced the very delineation of the concepts and questions that these three orientations imply. Badiou criticised what he saw as philosophy's linguistic turn and the "algorithmic or constructivist finitism"19 in mathematics. For a constructivist, "whatever is not distinguishable by a well-made language is not" ${ }^{20}$ and the language builds a

\footnotetext{
15 Badiou, Briefings on Existence: A Short Treatise on Transitory Ontology, p. 111.

16 Paul Benaceraff, Hilary Putnam (eds.), Philosophy of Mathematics, Cambridge University Press, Cambridge 1983, p. 30.

${ }_{17}$ Badiou, Briefings on Existence: A Short Treatise on Transitory Ontology, p. 91.

18 Ibid., 54 .

19 Ibid., 104.

20 Alain Badiou, Being and Event, Continuum, New York 2006, p. 283.
} 
proximity between the presentation and the representation. To these orientations of thought, Badiou opposed a philosophical doctrine in which "number is a form of being" ${ }^{21}$ and not a linguistic convention. If being qua being is an inconsistent multiplicity without the one, sets and numbers must be more than empty words.

Badiou's three major works are three different takes on this relation between mathematics and philosophy. Being and Event, by focusing on ontology, is grounded in the key notions of set theory and Paul Cohen's forcing. Logics of Worlds uses category theory in order to explain existence, or what there is. The Immanence of Truths creates a bridge between these two books by mobilising the theory of large cardinals. ${ }^{22}$ Each of these three books is cantered on a different notion: Being and Event on that of universality (the book posits the existence of universal and infinite truth procedures), Logics of Words on singularity (it questions how these truths appear in a given world), and finally, The Immanence of Truths on the notion of the absolute. By referring to cardinal numbers so large that they can approximate the entire universe of numericity, in the third volume Badiou tries to answer the question: "How do truths relate to the absolute?" According to Badiou, "neither universality, nor singularity have a constant explicit relation with infinity." ${ }^{23}$ The category of the absolute is necessary to connect these two categories. Without the notion of the absolute, a given set might be generic in one world and not in another one. What seems universal and infinite in our world could be merely our own, localised, and culturally-determined universalism. To a certain extent, Badiou invokes the absolute as a response to the criticism coming from the side of Anglo-Saxon empiricism and postcolonial studies. For he admits that "without grounding universality in the absolute, it becomes merely empirical." ${ }^{24}$ Thus, he describes the goal of The Immanence of Truths as "to examine what in the constitution of a truth makes it touch the absolute in such a manner that universality can be created and affirmed in singularity." ${ }^{25}$

\footnotetext{
${ }_{21}$ Alain Badiou, Number and Numbers, Polity, Cambridge 2008, p. 25.

22 Among the rare bibliographical references, Badiou cites Thomas Jech's Set Theory, Akihiro Kanamori's book on the Higher Infinite, and the work of Hugh Woodin.

23 Alain Badiou, L'Immanence des vérités, Fayard, Paris 2018, p. 515. [My translation.]

24 Interview with Alain Badiou on The Immanence of Truths, Paris 13 February 2018.

25 Ibid., Paris, 13 February 2018.
} 
In The Immanence of Truths, the category of the absolute appears marked by the capital letter V; V denotes the absolute class or the place of all thinkable forms of multiplicities. The absolute class $\mathrm{V}$ is not a mathematical object - a place where we can find all possible forms of the multiple cannot itself be a form of the multiple. $\mathrm{V}$ is an operator; it is not a mathematical object but "that from which we abstract mathematical objects. ${ }^{26}$ The absolute class $\mathrm{V}$ is the universe of thought; it is that from which we have to depart in order to think multiplicity.

In order to elucidate some of the paradoxes of the absolute class $\mathrm{V}$, it might be useful to return to the prehistory of this concept in Georg Cantor's philosophico-mathematical essays and correspondence. For although Cantor's set theory was later described as "naïve," some of his considerations manifest a striking similarity to the problems that Badiou faced. From Aristotle's failed attempt to solve Zeno's paradoxes until Cantor, the majority of Western philosophers had been contesting the existence of the actual infinite and had seen the potential infinite as the only imaginable infinite that could resolve these paradoxes. It was only with Georg Cantor's invention of set theory that the category of the actual infinite (the infinite as actually present, as "what there is") was brought back into the forefront and mathematicians and philosophers began to consider the infinite as a mathematical object. Cantor famously distinguished between cardinal and ordinal numbers, by naming the set of all natural numbers by Greek and Hebrew letters such as $\omega$ (the ordinality of this set) or $\aleph_{0}$ (its cardinality). Thanks to his discovery of the power set theorem, he was able to surpass the elementary infinite $\omega$ and build an entire hierarchy of the uncountable actual forms of infinity (beginning with the first uncountable infinite ordinal $\omega_{1}$.

In his 1887-88 text Mitteilungen zur Lehre vom Transfinitem, Georg Cantor defined the potential infinite as "an indeterminate, always finite, variable magnitude taking values which become either as small as we please or larger than any arbitrary finite bound." ${ }^{27}$ He described the actual infinity as a "constant quantum which is larger than any finite magnitude of the same kind." ${ }^{28}$ How were the potential and the actual infinity articulated in Cantor's work? Cantor men-

26 Ibid.

${ }_{27}$ Georg Cantor, “Mitteilungen zur Lehre vom Transfinitem”, in Gesammelte Abhandlungen Matematischen and Philosophischen Inhalts, Springer, Berlin 1932, p. 401. [My translation.]

28 Ibid., p. 401. [My translation.] 
tions that "a variable magnitude $\mathrm{x}$ successively taking the different finite whole number values $1,2,3 \ldots$..... represents a potential infinite, while the set (v) of all whole finite numbers, conceptually determined by a full conceptual law, offers the simplest example of an actual infinite quantum." ${ }^{29}$ In Mitteilungen, Cantor divided the infinite into the following categories:

- the potential infinite (i.e. the series of natural numbers 1, 2, 3...). Cantor remarked that this potential infinity is "improper" and it might even be better not to call it "infinite" at all; $3^{30}$

- the transfinite or increasable [vermehrbares] actual infinite. Cantor gives $\omega$, $\omega+1, \omega+2 \ldots$ among examples thereof;

- the absolute infinite or the true non-increasable [unvermehrbares] infinite. Cantor remarks regarding this form of infinity that "it is not possible to add to or to take away anything from its size and on the quantitative level it should be seen as the absolute maximum." ${ }^{11}$

Cantor states clearly that while the transfinite can be manipulated by mathematicians, the absolute infinity "eludes mathematical determination" ${ }^{22}$; it is not a mathematical object. More specifically, Cantor was convinced that the category of the absolute belongs to theology, and not to mathematics. The absolute inexists from the point of view of mathematics. Transfinities are forms of intermediate infinities that are actual without being absolute and are located between the potentiality of the improper infinite and the absolute. In his letter to Wundt of 5 October 1883, Cantor characterised the absolute as "what cannot be enlarged or perfected and is analogous to the 'absolute' in metaphysics. My proper infinite, or if you'd like, transfinite numbers w, w+1 are not 'absolute' because - although they are not finite - they can be increased. The absolute cannot be increased at all and therefore it is inaccessible to us." ${ }^{33}$ Elsewhere, Cantor famously declared that "the absolute can only be acknowledged [anerkannt] but never known [erkannt] and not even approximately known." ${ }^{34}$ We can subtract transfinite sets from the absolute, but as large as these sets might be, we will never even approximate

\footnotetext{
29 Ibid., p. 409. [My translation.]

30 Ibid., p. 404. [My translation.]

31 Ibid., p. 405. [My translation.]

32 Ibid. [My translation.]

33 Georg Cantor, Briefe, Springer, Berlin 1991, p. 139. [My translation.]

34 Georg Cantor, "Foundations of a General Theory of Manifolds: A Mathematico-Philosophical Investigation into the Theory of the Infinite”, p. 916.
} 
the whole universe of numericity. For this absolute universe of numbers is what Cantor described in his late correspondence as an "inconsistent multiplicity".

It is not always very obvious to see the correspondences between the actual and potential infinite and the various categories put forward by Cantor (improper infinite, transfinite, proper infinite). Ignacio Jané divides Cantor's work into two periods: "between the writing of Grundlagen and the appearance of Beiträge, Cantor conceived the absolute infinite as actually existing (although not as an object of mathematics, while after Beiträge (from 1897 on) he viewed the absolute infinite as existing only potentially." ${ }^{35}$ Jané remarks that the potentiality of the absolute infinite (which corresponds to what Badiou describes as the "absolute class V") guaranteed for Cantor the actual existence of the intermediate transfinities. In a letter to David Hilbert of 2 October 1897, Cantor emphasised that "the 'transfinite' coincides with what has since antiquity been called the 'actual infinite'," ${ }^{6}$ while sets such as the "set of all alephs" are absolutely infinite and cannot be thought of as existing together. Thus, it might seem that in Cantor's work the potential infinity did not disappear, it was merely transposed to a higher level.

In the letter to Richard Dedekind of 3 August 1899, Cantor delineated the distinction between consistent and inconsistent multiplicities. An inconsistent or "absolutely infinite" multiplicity is that in which "the assumption of "being-together' of all its elements would lead to a contradiction; thus, it is impossible to conceive this multiplicity as a unity, as a "finished thing,." ${ }^{37}$ The "epitome of all that is thinkable" ${ }^{38}$ is an inconsistent multiplicity. In consistent multiplicities, "the totality of the elements of the multiplicity can be thought without contradiction as 'being-together' so that it is possible to conceive it as 'a thing,." ${ }^{39}$ Consistent multiplicities can also be called sets. Following this distinction, Cantor

35 Ignacio Jané, “The Role of the Absolute Infinite in Cantor's Conception of Set”, Erkenntnis 41 (3/1995), p. 383.

36 Georg Cantor, "Letter to David Hilbert, 2 October 1897", in From Kant to Hilbert: A Sourcebook in the Foundations of Mathematics, Vol. II, ed. William Ewald, Clarendon Press, Oxford 2005, p. 928.

37 Georg Cantor, Briefe, p. 407. [My translation.] "Finished thing" is my translation of "ein fertiges Ding" in German.

38 Ibid., 407.

39 Ibid., 407. 
asked if the collection of all that is thinkable is a consistent multiplicity or an inconsistent one. Cantor indexed the system of all numbers, of all that is thinkable by the letter $\Omega$. He remarked that such a system forms the following increasing sequence:

$0,1,2,3 \ldots \omega_{0}, \omega_{0}+1, \ldots . \gamma$, and so on...

Then, he answered his question by asserting that $\Omega$ cannot be a consistent multiplicity (a set of all sets), because if $\Omega$ were consistent, for every well-ordered set there would have to be a number $\delta$ that would be bigger than all numbers contained in $\Omega$ and that would be its successor. This $\delta$ would be bigger than everything that is in $\Omega$, which is a contradiction since $\Omega$ is defined as the set of all sets. For this reason, $\Omega$ must necessarily be an inconsistent multiplicity and there cannot be a set of all sets..$^{40}$ Following such a trajectory of reasoning, we might get the impression that Cantor's thought began with potential infinities (the series of natural numbers 1, 2, 3...), then passed through an architecture of actual infinities $\left(\omega_{1}, \omega_{2}, \ldots\right)$, in order to finally fall back into the potentiality of $\Omega$.

\section{The absolute place and the hierarchy of the infinite}

Badiou's description of the whole universe of numericity as universe or place in line with recent mathematics might be his manner of avoiding the previously mentioned paradox of Cantor: the paradox in which $\Omega$ can be interpreted as a potential infinity that has merely been pushed to the higher level. Badiou remarks that the absolute class $\mathrm{V}$ is similar to what Plato describes as "the intelligible realm"41 [le lieu intelligible], which means the "non-representable place within which all representation is deployed." ${ }^{2} \mathrm{~V}$ is "the place of all that can validate the propositions about multiplicities as such." ${ }^{\prime \prime 3}$ It is "the place where the formal possibility of all existent multiplicities is thought, and which can be reduced to neither language nor the power of nothingness." ${ }^{44} \mathrm{~V}$ recalls Leibniz's "being of the possible"45 [l'être du possible] and Spinoza's "substance,"

\footnotetext{
40 Ibid., 408.

${ }_{41}$ Badiou, L'Immanence des vérités, p. 42. [My translation.]

42 Interview with Alain Badiou on The Immanence of Truths, Paris, 13 February 2018.

43 Badiou, L'Immanence des vérités, p. 40. [My translation.]

44 Ibid., p. 41. [My translation.]

45 Ibid., p. 41. [My translation.]
} 
with the only difference being that $\mathrm{V}$ cannot be identified to the intellect of God. In the absolute class $\mathrm{V}$, being and thinking are identical. By describing $\mathrm{V}$ as "the absolute ontological place, ${ }^{{ }^{4} 6}$ Badiou avoids collating $\mathrm{V}$ with the potential infinity of Cantor's $\Omega$. For if Cantor defined the actual infinity as a "constant quantum which is larger than any finite magnitude of the same kind," ${ }^{47} \mathrm{~V}$ might not be a quantum, but it is certainly constant and larger than any finite magnitude. In other words, the "absolute" means that $\mathrm{V}$ is a maximum, there is no $V_{v}$. A "place" can be conceived as being-together, thus, using this term to describe $\mathrm{V}$ as "place" enables its potentialisation to be avoided.

The absolute class $\mathrm{V}$ is stratified, it has the structure of an unattainable horizon; we can create higher and higher approximations of this horizon but we can never reach it. In mathematics, such a universe is generally represented as a triangle standing on its top. There is the horizon $\mathrm{V}$, and the approximations of this horizon: its sub-classes. If we consider, for instance, a class of all ordinals, which as such belongs to the absolute class $\mathrm{V}$, we see that the notion of class is based on a connection of intentional and extensional characteristics: a class is defined by its attributes (being an ordinal) and it also has an extensional relationship with other subclasses (the class of all ordinals belongs to V). However, to say that one class belongs to another class is nothing but a metaphor used by mathematicians because, strictly speaking, the relation of belonging exists only between sets. Understanding these approximations of the absolute and the closeness to the absolute was a major task of Badiou in The Immanence of Truths.

In the mentioned book, Badiou distinguishes four different kinds of the finite:

- the accessible finite (a new set can be invented only with the resources of the existing situation);

- the divisible finite (the decomposition of a large infinite set into smaller sets);

- the limited finite [le fini borné] (preferring totality to openness, the particular to the universal); and

- the finite that negates all absoluteness.

\footnotetext{
${ }^{46}$ Ibid., p. 42. [My translation.]

47 Cantor, "Mitteilungen zur Lehre vom Transfinitem”, p. 401. [My translation.]
} 
These four kinds of the finite are symmetrically juxtaposed with four different species of infinity organised in ascending order (from the smallest to the largest infinite). Each higher order of the infinite "finitises" the previous one.

\section{a) Inaccessible infinity or infinity via transcendence}

This elementary form of infinity is close to the potential infinite and is relatively small; "transcendent" means merely that we cannot gain access to it and that it can be defined through negation. In theology, the God transcendent to the human world might constitute an example of such an inaccessible infinity. In mathematical language, Badiou formalises the infinite via transcendence as the strongly inaccessible cardinal.

A strongly inaccessible cardinal $\kappa$

1) is superior to $\omega$;

2) is a limit cardinal;

3) is regular = it is bigger than the union of all cardinals smaller than $\kappa$;

4) is bigger than the cardinality of the power set of any cardinal that is smaller than this strongly inaccessible cardinal.

Badiou remarks that, for a long time, a strongly inaccessible cardinal has been seen as the limit of set theory. Had this cardinal $\kappa$ existed, we could find its corresponding class $V_{K}$ and the latter would become the model of all axioms of ZFC. However, according to Kurt Gödel's second incompleteness theorem, given a formal system containing basic arithmetic, it is impossible to prove its consistency from within that system. Therefore, the existence of inaccessible infinity cannot be proved from within the axioms of ZFC. Inaccessible infinity evokes Blaise Pascal's wager: we can only wager that God qua inaccessible infinity exists, without ever being able to possess a final proof of the existence thereof.

\section{b) The infinity defined by its indivisibility}

In The Immanence of Truths, Badiou compares this infinity to the division of God into a trinity in Christian theology and the related question of how it is possible that such a division does not diminish God's power. If we attempt to cut the "indivisible" infinity into very small parts, these parts will be always able to form a subset that will be of the same cardinality as the entire infinite set. To explain this kind of infinity, Badiou uses the Ramsey theorem. Frank P. Ramsey studied the first countable infinite $\omega$ and the possibility of dividing it by two. He realised 
that if this set is divided by two, it will always be possible to form a subset $\mathrm{H}$ that will belong to the same half of this divided set and will have same cardinality as the whole set (before division).

The Ramsey cardinal, devised by Paul Erdős and András Hajnal and named after Frank P. Ramsey, transposed the latter's discovery into the sphere of the uncountable infinite. According to Erdös and Hajnal, if we divide this uncountable infinite set by any number, it will always be possible to find a manner of classifying the parts into which it was divided and transform them into a subset of the initial set, a subset that is homogenous to the partition. Saying that this subset is homogeneous means that it has the same cardinality as the initially divided infinite set. Thus, the Ramsey cardinal evokes the idea of an infinite set that is so compact and dense and whose elements are in such proximity to each other that even if we cut it into small parts, a large infinite residual set will always escape our cutting.

Badiou mobilises the above-mentioned concepts in order to reflect on how emancipatory political movements could avoid capitalism's oppressive tendency to divide them into smaller parts. By helping to sow the division into any genuine emergent political movement, the dominant regime is able to preserve its sovereignty. The division is an operator of finitude. In contrast, any truth procedure will engender an infinity equal at least to the Ramsey cardinal. Any emancipatory political movement, any true "event", relates to the emergence of new forms of infinite truth procedures.

\section{c) The infinity of big parts}

This form of infinity invokes the question of what it means that something is close to the absolute, or that it is "almost" absolute. Are there any classes interior and inferior to V that can still express the absolute V? Can the absolute be approximated in any manner? Is there anything like bigness in itself?

On a formal level, Badiou attempts to respond to this question by using the difficult concept of the non-principal K-complete ultrafilter. A filter on a set is a mathematical apparatus helping us to distinguish small parts from the large ones; it works like a sieve that only catches large parts, while the small ones pass through. 
If we have a set $\mathrm{E}$, we call $a$ filter on $E$ a set $\mathrm{F}$ composed of parts of $\mathrm{E}$, which has the following properties:

1) It does not contain the empty set; the empty set must be "small".

2) It contains the set $E$ : the largest part.

3) If parts $A$ and $B$ belong to the filter, the filter also contains their intersection. In other words, if both $\mathrm{A}$ and $\mathrm{B}$ are large parts, their intersection will be large.

4) If the filter contains part $A$ and $A$ is included in part $B$, it must contain part $B$, because $B$ is bigger than $A$.

In order to transform this filter into an ultrafilter, a property of exhaustivity has to be added:

5) If we consider any part of $\mathrm{E}$, it either belongs to the ultrafilter or its complementary part (i.e. its negation) belongs to the ultrafilter. Thus, the ultrafilter exhausts everything that there is: either one element belongs to it or its opposite does.

A non-principal ultrafilter means:

6) that this ultrafilter does not contain any singleton (a set containing only one element). Badiou is particularly interested in this property for it enables him to disconnect the infinite from the one.

And finally, $\kappa$-complete

7) is a mathematical procedure of ultrafiltering constructing a huge cardinal $\kappa$ that has this non-principal $\kappa$-complete ultrafilter on itself. This mathematically complex section of the book translates into philosophical language as follows: the ultrafiltering engenders an infinite set so large that it exceeds the previous two forms of infinities and constitutes a testimony of the existence of the absolute class V. This set is "almost absolute"; it is a proof of the existence of the absolute class V. The statement "truths are absolute" is equivalent to the affirmation that the infinity of a truth is so large that it can attest to the existence of the absolute class V.

\section{d) The infinity defined by its proximity to the absolute}

This infinity corresponds to Badiou's theory of the attributes of the absolute and is elucidated in the most Spinozist part of the book. In this section, Badiou emphasises that the relationship between the absolute and one of its attributes implies the existence of a very large infinite set - a complete cardinal - that becomes witness to the existence of the absolute class V. Using Mostowski lemma and Jerzy Lós theorems, Badiou explains the mathematical concept of the elementary embedding, which plays a similar structural role in the book as forcing does in Being 
and Event. In simple words, elementary embedding is a mathematical procedure entailing taking a transitive sub-class of $\mathrm{V}$ - which we can call here $\mathrm{M}$ (e.g. a class of all ordinals because ordinals are defined by their transitivity) - and transforming it into a model of V. In this manner, the absolute class V will be embedded in one of its attributes, in the transitive sub-class $M$. There will be a relation $\mathrm{j}$ between $M$ and V. However, this relation $j$ will not be that of identity: V will remain different from the attribute M and contain sets that we cannot find in M. V is "embedded" in this class somewhat like an edifice is embedded in its concrete foundations.

\section{The attributes of the absolute and the philosopher's choice}

In Plato's vocabulary, we could say that this fourth kind of infinity participates in the absolute class V. If V is equivalent to Spinoza's notion of substance, the fourth infinity equals Spinoza's notion of the attribute of the absolute: the absolute expresses itself through its attributes but nevertheless remains separated from them. Or as Badiou remarks, "the expressive capacity of the absolute is intelligible for us only through the mediation of attributes." 48 Saying that we consider "all the sets" is a weak characteristic; it gives us a feeble understanding of the absolute. However, using an attribute such as the "class of all ordinals" can provide at least some grasp of the absolute because we possess a definition of an ordinal: we know that an ordinal is a set that is transitive and well-ordered by $\in$. Thus, by approaching the absolute through its attributes we are able to gain a certain and limited knowledge of the absolute. We can never entirely know the absolute as such, but we can at least approximate it through the use of attributes.

It would be interesting to compare Georg Cantor's own references to Spinoza to those of Badiou. For instance, in Foundations of a General Theory of Manifolds, Cantor averred that "an especially difficult point in Spinoza's system is the relationship of the infinite modes to the infinite one; it remains unexplained how and under what circumstances the finite can maintain its independence with respect to the infinite, or the infinite with respect to still higher infinities." alluded here to "Proposition 22" of Spinoza's Ethics, according to which "whatever follows from some attribute of God insofar as it is modified by a modification

48 Interview with Alain Badiou on The Immanence of Truths, Paris, 13 February 2018.

49 Cantor, "Foundations of a General Theory of Manifolds: A Mathematico-Philosophical Investigation into the Theory of the Infinite”, p. 892. 
which, through the same attribute, exists necessarily and is infinite, must also exist necessarily and be infinite." ${ }^{\circ 0}$ In contrast, in "Proposition 28," Spinoza postulated that "any thing which is finite and has a determinate existence, can neither exist nor be determined to produce an effect unless it is determined to exist and produced an effect by another cause, which is also finite and has a determinate existence." ${ }^{1}$ Thus, it seems that the infinite and the finite exist in Spinoza in two independent chains of causes and effects which do not interact with each other: on the one hand, the infinite attributes of the substance, on the other hand, the finite modes of our existence. To bridge these two chains, Spinoza proposed the concept of the "infinite mode," and yet he did not adequately explain how the infinite mode can engender the finite. The lack of connection between the finite and the infinite puzzled Cantor, as well as Badiou, who in his 1984-85 seminar remarked that in Spinoza's work "the finite produces the finite and the infinite produces the infinite. This is an enigmatic point." ${ }^{22}$

Badiou's concept of "oeuvre", presented in the concluding chapters of The Immanence of Truths, constitutes an endeavour to disentangle the unsolved problem of Spinoza. Badiou posits that it is necessary to "postulate that the working of a truth is subjectively structured in tension within a play of various distinct infinities, and the result is certainly a finite oeuvre, or in other words, its absoluteness is related to the fact that this finitude conquers the status of an oeuvre instead of being a simple waste [déchet] of the infinite. It is a finite result that reaches the level of its infinite causality because it inscribes itself into an attribute of the absolute." ${ }^{3}$ If truths, in Badiou's work, correspond to Spinoza's attributes of the substance, and the very procedures of these truths to infinite modes, the oeuvre is the finite mode engendered by the infinite. The oeuvre is a paradoxical finite fragment of reality that in spite of its finitude remains indexed to the absolute. "All oeuvre of truth is finite, singular, universal, and absolute," ${ }^{54}$ states Badiou. The indexation of the finite oeuvre by infinity makes it participate in

50 Benedictus de Spinoza, A Spinoza Reader: The Ethics and Other Works, Princeton University Press, Princeton 1994, p. 101.

$51 \quad$ Ibid., p. 103.

52 Alain Badiou, L’infini, Aristote, Spinoza, Hegel, Le Séminaire 1984-1985, Fayard, Paris 2016, p. 170.

53 Badiou, L'Immanence des vérités, p. 393. [My translation.]

54 Ibid., p. 512. [My translation.] 
the absolute. The oeuvre of the absolute is a manifestation of the connection between universality and singularity.

In The Immanence of Truths, the concept of the oeuvre is juxtaposed with that of a "waste" [déchet]. If the oeuvre is indexed to the absolute, the idiosyncratic property of the "waste" is that it can be covered by constructible sets, that it is nothing but "a mode of existence of multiples which have no other figure than to remain under the law of the world in which they appear." 55 The Immanence of Truths completes Badiou's critique of the linguistic orientation of philosophy by identifying finitude with the property of constructibility. A given set is finite, or "constructible" if all its elements can be defined by a given language. In the constructivist orientation of thought, the mathematical real is subjugated to language. Badiou remarks that "any set can become a material for covering and thus become finite if it has as its sole elements other multiplicities that constituted definable parts in an already pre-existing and finite set. Such finite set will be said to be 'constructible'. ${ }^{\prime 6}$ Constructivism operates through the logic of "covering" [le recouvrement]: a new potentially infinite multiple is "covered" by already existing multiples. An emerging large infinity is rendered finite by being covered by a multiplicity of finite sets. The inconsistent multiplicity is transformed into a multiplicity of consistent ones. In mathematical terminology, the hypothesis that the word "set" signifies a finite or constructible set has been generally marked by the capital letter $\mathrm{L} . \mathrm{V}=\mathrm{L}$ denotes the hypothesis of a constructible universe, the idea that there are no actual infinities and that the only things that exist are finite, constructible sets. If $\mathrm{V}=\mathrm{L}$ were true, Georg Cantor's Continuum Hypothesis (there is no set that is greater than the set of all integers and smaller than the set of all real numbers) would be necessarily and logically valid.

Badiou admits, in Chapter 19 of The Immanence of Truths that from the mathematical point of view, both options of accepting and rejecting constructivism $(\mathrm{V}=$ L) are possible: on the one hand, Kurt Gödel proved that it is possible to preserve the consistency of ZFC set theory by adding to it the axiom of constructibility; on the other hand, Paul Cohen, in the 196os, invented the technique of forcing, thus showing that it was possible to admit the existence of non-constructible generic multiplicities. Both options are equally admissible for working mathematicians.

\footnotetext{
$55 \quad$ Ibid., p. 511. [My translation.]

56 Ibid., p. 240. [My translation.]
} 
Thus, he is left with nothing but a "crucial choice" between the constructible or truly infinite and a generic orientation of thought. He decides in favour of Cohen against Gödel. The affirmation that "there is the infinite" ${ }^{77}$ is nothing but a purely philosophical act, in which The Immanence of Truths originates. Such an act can be justified only a posteriori, by the abundance of its consequences. Badiou decides as a philosopher, and not as a mathematician, that there must be something unnamable or indiscernible that cannot be described by the language of the dominant order. Once again, he subordinates mathematics to philosophy. The task of the philosopher might be to cut the Gordian knot that mathematics cannot untie. Such cutting operates in Badiou's thinking by finding in Spinoza resources to think an actual non-denumerable infinity and turning them against the ideas of Leibniz, by privileging the realist orientation of the matheme over the supremacy of language. Maintaining philosophy in close relation to its mathematical condition is necessary for freeing thinking from its capture by the linguistic turn. Mathematics is but Badiou's shield against the reduction of thought to the constructible; it is in this sense that the three volumes of Being and Event could also be renamed "Three Critiques of the Constructible". Philosophy is not sutured to anything - not even to mathematics - it is free and bound only by its consistency while operating in a necessarily incomplete field.

\section{References}

Badiou, Alain, Being and Event, Continuum, New York 2006

- Briefings on Existence: A Short Treatise on Transitory Ontology, State University of New York Press, Albany 2006

- L'Immanence des vérités, Fayard, Paris 2018

L’infini, Aristote, Spinoza, Hegel, Le Séminaire 1984-1985, Fayard, Paris 2016

- Number and Numbers, Polity, Cambridge 2008

- Interview with Alain Badiou on The Immanence of Truths, Paris, 13 February 2018

- Benaceraff, Paul, Hilary Putnam (eds.), Philosophy of Mathematics, Cambridge University Press, Cambridge 1983

Beránková, Jana, “Communism is a New Idea, Interview with Alain Badiou by Jana Beránková”, Contradictions 2 (2/2018), pp. 117-132

Cantor, Georg, “Fondements d'une théorie générale des ensembles”, Cahiers pour l’Analyse (10/1969), pp. 35-52.

- "Foundations of a General Theory of Manifolds: A Mathematico-Philosophical Investigation into the Theory of the Infinite", in From Kant to Hilbert: A Sourcebook in the Foundations of Mathematics, Vol. II, ed. William Ewald, Clarendon Press, Oxford 2005

$57 \quad$ Ibid., p. 265. [My translation.] 
- “Mitteilungen zur Lehre vom Transfinitem”, in Gesammelte Abhandlungen Matematischen and Philosophischen Inhalts, Springer, Berlin 1932

Gödel, Kurt “What is Cantor's Continuum Problem?” in Collected Works, Vol. II, Publications 1938-1974, Oxford University Press, Oxford 1990

Jane, Ignacio, “The Role of the Absolute Infinite in Cantor's Conception of Set”, Erkenntnis 41 (3/1995)

Spinoza, Benedictus de, A Spinoza Reader: The Ethics and Other Works, Princeton University Press, Princeton 1994 